\title{
Detection of defects in CFRP impact damage specimens by using infrared thermography
}

\author{
, Heesang Park1, Manyong Choi2†, Junghak Park2, KooAhn Kwon2 and HyunChul Jung3 \\ 1 Development of department Korea Research Institute of Smart Material and Structures System \\ Association, Daejeon, Korea, \\ $2^{+}$Safety measurement center, Korea research Institute of Standards and Science, Daejeon, Korea \\ Phone: +82 042868 5257, Fax: +82 042868 5650; e-mail: \\ mychoi@kriss.re.kr,m55nring@naver.com \\ 3Department of Mechanical Engineering, Chosun National University, Gwangju, Korea
}

\footnotetext{
Abstract: Recently, composite materials have been usually used in the main wings, ailerons and fuselages of aircrafts and the rotor blades of helicopters.[1] In the case of an aircraft using composite material for rapid-moving structures, their physical reactions to external shock also become different from those of the existing metal structures. In this connection, this study applied impact load to CFRP composite specimens by using the infrared thermography technology and different light sources, and then investigated the method for detecting damage to composite materials more quickly and more accurately.
} 